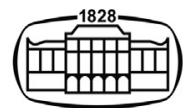

AKADÉMIAI KIADÓ

Journal of Psychedelic Studies

5 (2021) 2, 69-82

DOI:

10.1556/2054.2021.00166

(C) 2021 The Author(s)

\section{ORIGINAL RESEARCH} PAPER

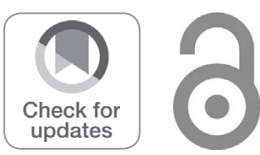

\title{
Racial/ethnic differences in prevalence of hallucinogen use by age cohort: Findings from the 2018 National Survey on Drug Use and Health
}

\author{
ZOE W. JAHN ${ }^{1}$, JOEL LOPEZ ${ }^{2}$, SARA DE LA SALLE ${ }^{3}$, \\ SONYA FABER ${ }^{4}$ and MONNICA T. WILLIAMS ${ }^{3,5^{*}}$ ๑) \\ ${ }^{1}$ Department of Physiology and Neurobiology, University of Connecticut, USA \\ ${ }^{2}$ Department of Psychological Sciences, University of Connecticut, USA \\ ${ }^{3}$ School of Psychology, University of Ottawa, Ontario, Canada \\ ${ }^{4}$ Angelini Pharma, Rome, Italy \\ ${ }^{5}$ Department of Cellular and Molecular Medicine, University of Ottawa, Ontario, Canada \\ Received: December 23, 2020 • Revised manuscript received: June 8, 2021 • Accepted: June 14, 2021 \\ Published online: July 8, 2021
}

\begin{abstract}
Background: Few studies have assessed the epidemiology of hallucinogenic substance use among racial and ethnic groups of varying age cohorts. Use of psychedelic substances may differ among people of color (POC), due to factors such as stigma and discriminatory drug enforcement practices against POC. The lack of inclusion of POC in psychedelic research further underscores the importance of identifying differences in use among racial/ethnic groups and age cohorts. Methods: Data from the 2018 National Survey on Drug Use and Health (NSDUH) was used for this analysis ( $N=56,313$, unweighted), representative of the non-institutionalized U.S. population. Proportions of lifetime hallucinogen use by race/ethnicity were compared. Proportions of past year rates of use were compared to examine differences by race/ethnicity and age cohort. Results: Approximately $15.9 \%$ of the U.S. population over 12 had used a hallucinogen at some point in their lifetime and $2.0 \%$ had used in the past year. Lifetime hallucinogen use was most prevalent among non-Hispanic White and multi-racial individuals, while Black/African Americans reported the lowest rates of use. White and multi-racial groups also reported the highest proportions of past year use among 12-34 year olds, and White individuals reported the highest proportions among 35-49 year olds. Hispanic individuals reported higher proportions of use among the 12-17 cohort, but lower proportions among the $26-49$ year old cohorts. Black/African Americans reported the lowest rates of past year use among the 12-25 year old cohorts. 50+ and older cohorts reported the lowest rates of hallucinogen use in the past year. Limitations: Data is crosssectional and self-reported. "Race" is a social construction is subject to change over time, and NSDUH ethnoracial categories are limited. Institutionalized populations are not included in the study. Conclusions: Significant differences in hallucinogen use among ethnoracial groups by substance and age cohorts were observed. Findings from this work may inform education, interventions, and therapeutic psychedelic research.
\end{abstract}

\section{KEYWORDS}

substance use, hallucinogens, psychedelics, ethnic minorities, ethnic differences

*Corresponding author. Tel.: +1343 961 1290; fax: +16135625169. E-mail: Monnica.Williams@u0ttawa.ca

\section{INTRODUCTION}

A hallucinogen, also commonly known as a psychedelic, is a psychoactive substance that elicits an altered state of consciousness in the user; this altered state may involve visual hallucinations, distorted sensory perception, and differences in thought patterns 
(Nichols, 2004). Although hallucinogen use only became popular in the United States in the last century, psychedelic use dates back millennia within global history (Labate \& Cavnar, 2016). The epidemiology of hallucinogen use is especially important to study as psychedelics are increasingly integrated into Western medical practice and are being recognized for their therapeutic properties (Luoma, Chwyl, Bathje, Davis, \& Lancelotta, 2020). Nonetheless, hallucinogens can be problematic, especially given the safety and legal issues associated with illicit use.

\section{History of global hallucinogen use}

Evidence of hallucinogen use exists throughout nearly all of recorded global human history. Egyptian, Mesoamerican, and Greek empires utilized various naturally occurring psychoactive plant species in spiritual practice to further their understanding of human consciousness and develop explanations to phenomenon unbeknownst to them (AbdelAzeem, Abdel-Azeem, \& Blanchette, 2016; Klein et al., 2002; Nemu, 2019; Webster, 1999). Additionally, indigenous communities in various regions employ substances such as Ayahuasca, Peyote, and Ibogaine in traditional healing ceremonies today (Dyck, 2016; Jay, 2019). Throughout North America, a number of Native American Churches in both the United States and Canada use Peyote to initiate spiritual healing (Labate \& Cavnar, 2016), while sects of the Santo Daime Church and indigenous First Nation communities practice Ayahuasca ceremonies (Thomas, Lucas, Capler, Tupper, \& Martin, 2013).

\section{U.S. perspectives on hallucinogen use}

In the 1950's, U.S. research surrounding the clinical application of psychedelic medicine skyrocketed, and thousands of research studies were published on the many uses of lysergic acid diethylamide (LSD) alone (Yensen, 1985). Unfortunately, these new explorations were short-lived; the 1970's government-imposed "War on Drugs" brought a majority of psychedelic research to a halt. In an effort to decrease illicit drug use among the population, the government enacted a system of control which disproportionately targeted and oppressed low-income Latinx and Black communities (Hall, 1997; Rosino \& Hughey, 2018), and it is still in effect today (Alexander, 2010).

Disparities in U.S. incarceration rates paired with societal stigma created by the War on Drugs have led to various stereotypical beliefs surrounding which ethnoracial groups more often use and abuse certain substances (Alexander, 2010). Racialized groups including Blacks and Hispanics have been more often targeted by the justice system for criminal behavior associated with illegal drug use (Beckett, Nyrop, \& Pfingst, 2006; Tonry, 2010; Welch, Payne, Chiricos, \& Gertz, 2011), while White Americans and "model minorities" (e.g., Chinese and Japanese Americans), who have been less frequently targeted, are often perceived as the opposite (Chou \& Feagin, 2015). Further, people of color (POC) may have developed their own stereotypes about these substances and who uses them, which may influence usage (Rigg, 2017). Neglect of POC from psychedelic medical research further underscores the importance of examining such populations in substance use analysis (Michaels, Purdon, Collins, \& Williams, 2018).

Age is an additional identifying parameter that contributes to the intersectional identity of any given individual and must be considered in the context of hallucinogen use. Age influences access to certain hallucinogenic substances, and psychedelic stigmas might affect older and younger generations differently. For example, college-aged populations may be more involved in substance experimentation due to American college cultural norms combined with newfound independence that many of these young adults experience. An examination of 2019 monthly use of marijuana and various other illicit drugs reveals that the highest use is among those in their early and mid-20s (Schulenberg et al., 2020). However, research indicates that over the last 20 years, the fastest growing group of marijuana users has been the over 50 population (Lloyd \& Striley, 2018).

Furthermore, it is also possible that varying age cohorts would exhibit different patterns of use based on hallucinogenic availability or psychedelic stigma in the past several decades, for example, generational opinions due to the War on Drugs or the "Just Say No" campaign (Shalit, Rehm, \& Lev-Ran, 2019). A 2013 report (Krebs \& Johansen, 2013) estimated lifetime psychedelic use by age based on 2010 National Survey on Drug Use and Health (NSDUH) found that younger (age 21-49) and older (age 50-64) adults have had the same frequency of psychedelic use. The same report found that younger adults more often used psilocybin mushrooms, whereas older adults more often used LSD and mescaline (Krebs \& Johansen, 2013). Possible explanations for these findings could be that young adults more often utilize the ever-expanding catalog of home mushroom cultivation methods found online (Kristinsson, 2008), and that older adults were most prominently exposed to LSD during the initial psychedelic popularity prior to the enactment of the War on Drugs (Park, 2019).

Although multiple cumulative effects have led to decreased psychedelic use over time, some degree of illicit hallucinogen use has persisted. Studies conducted in the last decade have demonstrated that psychedelics are particularly effective in treating disorders when paired with psychotherapy in a clinical setting, such as: PTSD (Mithoefer et al., 2019; Ot'alora et al., 2018), depression (Carhart-Harris et al., 2016; Davis et al., 2020), OCD (Moreno, Wiegand, Taitano, \& Delgado, 2006), end-of-life anxiety (Griffiths et al., 2016), and substance use disorders (Johnson, Garcia-Romeu, Cosimano, \& Griffiths, 2014; Sessa et al., 2021). Most notably, the FDA designated MDMA-assisted psychotherapy a breakthrough therapy for treatment-resistant PTSD (Burns, 2017), and the same designation was granted to psilocybin-assisted psychotherapy in the treatment of major depressive disorder (Patterson, 2019). This research has garnered a great deal of positive notoriety from leading news outlets, and psychedelic substances are steadily becoming a household topic of discussion. 


\section{Purpose of this study}

National statistics show that various U.S. ethnoracial groups use substances at equivalent rates, although this varies by type of substance and age group (e.g., McCabe et al., 2007; SAMHSA, 2018; Shalit et al., 2019). When examining hallucinogen use specifically, there is very little information about use by people of color. It is unknown what specific ethnoracial groups are most likely to use these substances across age groups. This makes it difficult to account for differences in criminalization of certain minority groups, how to target interventions, and how to understand the lack of people of color in psychedelic research trials.

Although self-reported hallucinogen use data is available to the public through the Substance Abuse and Mental Health Services Administration (SAMHSA) database with statistics from the 2018 National Survey of Drug Use and Health (NSDUH), there is a lack of scientific literature that analyzes this data to explore these demographic differences among users. Based on related findings in the research literature (McCabe et al., 2007; Shalit et al., 2019), we hypothesize that most ethnoracial groups will use hallucinogens at a decreased rate in comparison to the general population and Non-Hispanic White Americans (with exceptions possibly among Native groups for ceremonial practice). Therefore, data analysis is needed to quantify usage patterns among various ethnoracial and age groups. A better understanding of which ethnic groups and age cohorts use hallucinogens will benefit researchers, clinicians, policy makers and health/social workers in pursuit of youth interventions, treatment program development, and psychedelic research endeavors.

\section{METHODS}

\section{Data source}

Data from NSDUH, which is partnered with SAMHSA, was used for this analysis $(N=56,313)$. Weighted data $(N=$ $273,753,043)$ was utilized in order to properly represent target populations and in order to account for disproportionate sampling by age group (Center for Behavioral Health Statistics and Quality, 2019). These anonymized, public-use data files are available for research purposes and can be accessed through the SAMHSA website (SAMHSA, 2018).

This annual survey collects nationally representative information on estimates of drug use and mental illness of the civilian, non-institutionalized population of the United States, aged 12 and older. Most of the survey questions were administered using the Audio-Computer Assisted SelfInterview (ACASI) method in which participants listen to pre-recorded questions through headphones and respond directly on a laptop. This method is believed to increase the levels of honest reporting of illicit drug use and other sensitive behaviors as it allows for more private and confidential responses (Center for Behavioral Health Statistics and Quality, 2015). Detailed information on sampling and data collection methods, confidentiality, and informed consent are described in the supporting documentation and codebook that accompany the public use data files (SAMHSA, 2018).

For the purposes of this investigation, the selected variables were 1) Hispanic Origin and Race (White American, Black/African American, Native American/Alaska Native, Pacific Islander/Native Hawaiian, Asian American, More than One Race, and Hispanic American, 2) Age Category (12-17, 18-25, 26-34, 35-49, 50+), 3) Lifetime (i.e., 'Ever Used'; use of specific substance at least once in the respondent's lifetime) Hallucinogen use, and 4) 'Past Year' (i.e., use of specific substance at least once in the past 12 months) Hallucinogen use. The 'hallucinogens' category in the survey includes: LSD (“Acid”), phenylcyclohexyl piperidine (PCP; (“Angel Dust”), Peyote, Mescaline, Psilocybin, MDMA ("Ecstasy"), Ketamine, DMT (including AMT and FOXY), Salvia Divinorum (hallucinogenic herbal mint), and 'Other Hallucinogen'.

\section{Data analysis}

Sampling and analytical weights (design-based, adjustment factors to adjust for nonresponse, to poststratify to known population control totals, and to control for extreme weights) were computed by the Substance Abuse and Mental Health Services Administration (SAMHSA, 2018) and made available through the Public-use Data Analysis System. Sampling weight methodology is described in detail within the 'Development of Analysis Weights' section of the National Survey on Drug Use and Health Methodological Summary and Definitions file (SAMHSA, 2019). The census control totals (by age, race, gender, and Hispanic origin) for the 2018 NSDUH weights were based on population estimates from the 2010 decennial census.

Proportions (\%) of lifetime users vs. non-users by ethnoracial identity were described in order to establish overall differences in use among these groups. Next, past year use was examined in terms of age cohort and ethnoracial identity. The ethnoracial categories were White American (nonHispanic), Black/African American (non-Hispanic), Native American (including Alaska Native, non-Hispanic), Pacific Islander (including Native Hawaiian, non-Hispanic), Asian American (non-Hispanic), More than One Race (non-Hispanic), and Hispanic American (any race). Associations between the five age categories and the seven ethnoracial categories were established with cross-tabulation. Wald ChiSquare Test of Associations were used to test statistical significance of the cross-tabulation ( $\alpha<0.01$ level) to determine if there was a significant difference between one or more prevalence estimates in each category. Differences in proportions between groups were considered statistically significant at the 95\% $(1-\alpha[0.05])$ level if the 95\% confidence intervals did not overlap, as has been done in previous work (Pouget, Fong, \& Rosenblum, 2018).

Participants who answered, "I don't know" to questions about use were tallied as an affirmative response, and participants refusing to answer were not counted. There were relatively few people who gave these sorts of responses 
(Refused: $N=1,688 ;<0.000006 \%$; Blank: $N=825,162$; $0.3 \%$ ) such that including or excluding them did not notably change the results.

\section{RESULTS}

\section{Patterns of use vs. non-use}

In a survey of all respondents, $15.9 \%$ of the population reported that they had used hallucinogens in their lifetime (Fig. 1). There were significant differences between prevalences $(\mathrm{F}[18,50]=57.4, P<0.0001)$. The White American (non-Hispanic), Native American (which includes Alaska Native), Pacific Islander (which includes Native Hawaiian), More than One Race, and Hispanic American groups reported significantly higher use than the Black American and Asian American groups. The White American, Native American, and More than One Race also reported significantly higher use than the Hispanic group. Percentages of lifetime use $( \pm 95 \%$ C.I.) by substance and by race/ethnicity group (all age cohorts collapsed) are detailed below in Table 1 .

In terms of the type of psychedelic substance used, White Americans used significantly more LSD and PCP than any other group. White Americans and mixed race individuals used more mescaline, psilocybin, and DMT than other groups. Multi-racial individuals used the most MDMA, ketamine, salvia, and other hallucinogens when compared to other groups. Native Americans used more peyote than the other groups.

The most popular hallucinogen for White Americans, Pacific Islanders, and multi-racial individuals was LSD $(13.0 \%, \quad 12.6 \%$ and $14.5 \%$ respectively). For Hispanic Americans, Black Americans, and Asian Americans it was MDMA (6.3\%, 4.4\%, and 3.5\%, respectively), and for Native Americans it was peyote (7.9\%). The least popular psychedelics for White Americans and multi-racial individuals were other types of hallucinogens $(1.1 \%$ and $1.7 \%$, respectively) and DMT/AMT/FOXY (1.3\% and 1.7\%, respectively). DMT was also the least popular hallucinogen for Black Americans, Native Americans, and Hispanic Americans $(0.1 \%, 0.9 \%$, and $0.8 \%$, respectively), while for Pacific
Islanders it was ketamine (0.03\%) and for Asian Americans it was peyote $(0.2 \%)$.

\section{Past year use by age cohort and ethnoracial identity}

Approximately $2.0 \%$ of the population reported that they had used a hallucinogenic substance in the past year. There were significant differences between prevalences of both use $(\mathrm{F}[24,50]=9.2, P<0.0001)$ and non-use $(\mathrm{F}[24,50]=$ 102.7, $P<0.0001$ ). Proportions of all survey respondents who had used a hallucinogen in the past year, grouped by age cohort and ethnoracial identity, are presented in Table 2 and displayed graphically in Fig. 2.

Among 12-17 year olds, the lowest reported use was among Black youth (0.3\%), who reported significantly lower use than their White $(1.8 \%)$, multi-race $(2.0 \%)$, and Hispanic (1.4\%) counterparts. The age cohort with the most differences in proportions of use was the 18-25 year old group. Multi-race individuals reported the highest proportion of use (15.0\%), followed by Non-Hispanic White (8.5\%) and Asian individuals (6.2\%). Those in the Black and Hispanic groups reported the lowest rates of use $(3.3 \%$ and $4.0 \%$, respectively). Among 26-34 year olds, White (5.1\%) and multi-race (7.2\%) individuals reported significantly higher use as compared to Hispanic (2.7\%) individuals. White $(1.6 \%)$ individuals also reported significantly higher use among 35-49 year olds as compared to Asian $(0.5 \%)$ and Hispanic $(0.5 \%)$ individuals. Finally, there were no significant differences between groups in the 50 and older age cohort (Table 2).

\section{Lifetime use by age cohort and ethnoracial identity}

Approximately $16.0 \%$ of the population reported that they had used a hallucinogenic substance at least once in their lifetime. There were significant differences between prevalences of both use (F $[24,50]=9.3, P<0.0001)$ and non-use $(\mathrm{F}[24,50]=87.5, P<0.0001)$. Proportions of all survey respondents who had used a hallucinogen in their lifetime, grouped by age cohort and ethnoracial identity, are presented in Table 3.

Among White Americans (28.7\%), Black Americans (11.7\%), Native Americans (36.5\%), Hispanic Americans

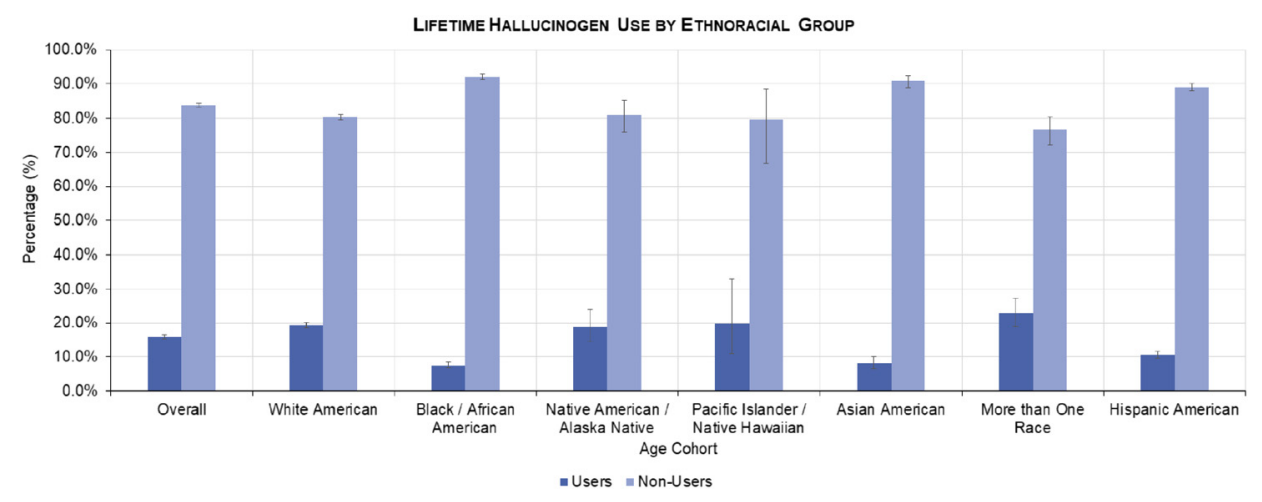

Fig. 1. Lifetime hallucinogen use by ethnoracial identity. A small number of respondents ( $<1 \%$ from each ethnoracial group) left the survey blank or refused to answer (omitted from figure) 
Table 1. Percent ( $\pm 95 \%$ C.I.) lifetime hallucinogen use by substance and race/ethnicity (weighted)

\begin{tabular}{|c|c|c|c|c|c|c|c|c|}
\hline Substance/race & $\begin{array}{c}\text { White } \\
\text { American }\end{array}$ & $\begin{array}{c}\text { Black/ } \\
\text { African } \\
\text { American }\end{array}$ & $\begin{array}{c}\text { Native } \\
\text { American/ } \\
\text { Alaska Native }\end{array}$ & $\begin{array}{c}\text { Pacific } \\
\text { Islander/Native } \\
\text { Hawaiian }\end{array}$ & $\begin{array}{c}\text { Asian } \\
\text { American }\end{array}$ & $\begin{array}{l}\text { More than } \\
\text { One Race }\end{array}$ & $\begin{array}{l}\text { Hispanic } \\
\text { American }\end{array}$ & All \\
\hline$N$ & $170,724,451$ & $32,944,516$ & $1,610,435$ & $1,024,328$ & $15,575,570$ & $5,241,610$ & $46,632,133$ & $273,753,043$ \\
\hline LSD (“Acid”) & $\begin{array}{c}\mathbf{1 2 . 9 9 \%} \\
(12.37 \%- \\
13.64 \%)\end{array}$ & $\begin{array}{c}\mathbf{3 . 0 7 \%} \\
(2.43 \%- \\
3.87 \%)\end{array}$ & $\begin{array}{c}\mathbf{8 . 4 4 \%} \\
(5.62 \%- \\
12.49 \%)\end{array}$ & $\begin{array}{c}\mathbf{1 2 . 6 2 \%} \\
(5.23 \%-27.45 \%)\end{array}$ & $\begin{array}{c}\mathbf{3 . 5 2 \%} \\
(2.07 \%- \\
5.92 \%)\end{array}$ & $\begin{array}{c}\mathbf{1 4 . 4 8 \%} \\
(11.30 \%- \\
18.38 \%)\end{array}$ & $\begin{array}{c}\mathbf{6 . 0 0 \%} \\
(5.32 \%- \\
6.76 \%)\end{array}$ & $\begin{array}{l}\mathbf{1 0 . 0 7 \%} \\
(9.56 \%- \\
10.60 \%)\end{array}$ \\
\hline PCP (“Angel dust”) & $\begin{array}{c}2.75 \% \\
(2.44 \%- \\
3.09 \%)\end{array}$ & $\begin{array}{c}\mathbf{1 . 6 0 \%} \\
(1.20 \%- \\
2.14 \%)\end{array}$ & $\begin{array}{c}\mathbf{0 . 8 9 \%} \\
(0.31 \%- \\
2.50 \%)\end{array}$ & $\begin{array}{c}\mathbf{0 . 3 9 \%} \\
(0.08 \%-1.85 \%)\end{array}$ & $\begin{array}{c}3.32 \% \\
(1.87 \%- \\
5.84 \%)\end{array}$ & $\begin{array}{c}3.32 \% \\
(1.87 \%- \\
5.84 \%)\end{array}$ & $\begin{array}{c}1.71 \% \\
(1.19 \%- \\
2.45 \%)\end{array}$ & $\begin{array}{c}2.30 \% \\
(2.08 \%- \\
2.55 \%)\end{array}$ \\
\hline Peyote & $\begin{array}{c}2.96 \% \\
(2.66 \%- \\
3.29 \%)\end{array}$ & $\begin{array}{c}\mathbf{0 . 3 2 \%} \\
(0.14 \%- \\
0.74 \%)\end{array}$ & $\begin{array}{c}7.90 \% \\
(5.10 \%- \\
12.05 \%)\end{array}$ & $\begin{array}{c}\mathbf{0 . 9 8 \%} \\
(0.22 \%-4.23 \%)\end{array}$ & $\begin{array}{c}\mathbf{0 . 1 9 \%} \\
(0.08 \%- \\
0.45 \%)\end{array}$ & $\begin{array}{c}4.62 \% \\
(3.14 \%- \\
6.74 \%)\end{array}$ & $\begin{array}{c}1.37 \% \\
(0.91 \%- \\
2.08 \%)\end{array}$ & $\begin{array}{c}2.27 \% \\
(2.07 \%- \\
2.49 \%)\end{array}$ \\
\hline Mescaline & $\begin{array}{c}3.75 \% \\
(3.36 \%- \\
4.18 \%)\end{array}$ & $\begin{array}{c}\mathbf{0 . 9 2 \%} \\
(0.56 \%- \\
1.51 \%)\end{array}$ & $\begin{array}{c}\mathbf{1 . 5 0 \%} \\
(0.62 \%- \\
3.60 \%)\end{array}$ & $\begin{array}{c}\mathbf{0 . 0 3} \% \\
(0.00 \%-0.21 \%)\end{array}$ & $\begin{array}{c}\mathbf{0 . 5 4 \%} \\
(0.16 \%- \\
1.84 \%)\end{array}$ & $\begin{array}{c}\mathbf{3 . 5 8 \%} \\
(2.37 \%- \\
5.37 \%)\end{array}$ & $\begin{array}{c}1.29 \% \\
(0.87 \%- \\
1.91 \%)\end{array}$ & $\begin{array}{c}2.77 \% \\
(2.53 \%- \\
3.05 \%)\end{array}$ \\
\hline Psilocybin & $\begin{array}{c}\mathbf{1 2 . 3 3 \%} \\
(11.75 \%- \\
12.94 \%)\end{array}$ & $\begin{array}{c}1.57 \% \\
(1.22 \%- \\
2.00 \%)\end{array}$ & $\begin{array}{c}7.86 \% \\
(5.26 \%- \\
11.60 \%)\end{array}$ & $\begin{array}{c}\mathbf{8 . 8 7 \%} \\
(3.79 \%-19.41 \%)\end{array}$ & $\begin{array}{c}3.51 \% \\
(2.59 \%- \\
4.74 \%)\end{array}$ & $\begin{array}{l}12.33 \% \\
(9.73 \%- \\
15.51 \%)\end{array}$ & $\begin{array}{c}5.20 \% \\
(4.46 \%- \\
6.05 \%)\end{array}$ & $\begin{array}{c}\mathbf{9 . 2 8 \%} \\
(8.90 \%- \\
9.67 \%)\end{array}$ \\
\hline MDMA ("Ecstasy") & $\begin{array}{c}\mathbf{8 . 4 4 \%} \\
(8.00 \%- \\
8.91 \%)\end{array}$ & $\begin{array}{c}4.35 \% \\
(3.78 \%- \\
5.00 \%)\end{array}$ & $\begin{array}{c}\mathbf{5 . 9 7 \%} \\
(3.79 \%- \\
9.28 \%)\end{array}$ & $\begin{array}{c}\mathbf{1 0 . 1 2 \%} \\
(5.48 \%-17.94 \%)\end{array}$ & $\begin{array}{c}4.62 \% \\
(3.79 \%- \\
5.63 \%)\end{array}$ & $\begin{array}{c}9.52 \% \\
(7.80 \%- \\
11.58 \%)\end{array}$ & $\begin{array}{c}\mathbf{6 . 3 4 \%} \\
(5.61 \%- \\
7.14 \%)\end{array}$ & $\begin{array}{c}7.38 \% \\
(7.03 \%- \\
7.75 \%)\end{array}$ \\
\hline Ketamine & $\begin{array}{c}1.62 \% \\
(1.43 \%- \\
1.83 \%)\end{array}$ & $\begin{array}{c}\mathbf{0 . 3 2 \%} \\
(0.20 \%- \\
0.49 \%)\end{array}$ & $\begin{array}{c}1.40 \% \\
(0.78 \%- \\
2.50 \%)\end{array}$ & $\begin{array}{c}\mathbf{0 . 0 3} \% \\
(0.00 \%-0.21 \%)\end{array}$ & $\begin{array}{c}\mathbf{0 . 3 0 \%} \\
(0.14 \%- \\
0.66 \%)\end{array}$ & $\begin{array}{c}\mathbf{2 . 0 3} \% \\
(1.31 \%- \\
3.13 \%)\end{array}$ & $\begin{array}{c}\mathbf{1 . 1 3 \%} \\
(0.83 \%- \\
1.53 \%)\end{array}$ & $\begin{array}{c}1.30 \% \\
(1.16 \%- \\
1.46 \%)\end{array}$ \\
\hline DMT, AMT, FOXY & $\begin{array}{c}1.32 \% \\
(1.14 \%- \\
1.52 \%)\end{array}$ & $\begin{array}{c}\mathbf{0 . 1 4 \%} \\
(0.07 \%- \\
0.26 \%)\end{array}$ & $\begin{array}{c}\mathbf{0 . 8 6 \%} \\
(0.36 \%- \\
2.03 \%)\end{array}$ & $\begin{array}{c}\mathbf{0 . 7 7 \%} \\
(0.13 \%-4.55 \%)\end{array}$ & $\begin{array}{c}\mathbf{0 . 3 2 \%} \\
(0.16 \%- \\
0.67 \%)\end{array}$ & $\begin{array}{c}1.71 \% \\
(1.03 \%- \\
2.83 \%)\end{array}$ & $\begin{array}{c}\mathbf{0 . 7 9 \%} \\
(0.58 \%- \\
1.08 \%)\end{array}$ & $\begin{array}{c}1.03 \% \\
(0.91 \%- \\
1.17 \%)\end{array}$ \\
\hline Salvia Divinorum & $\begin{array}{c}2.45 \% \\
(2.22 \%- \\
2.70 \%)\end{array}$ & $\begin{array}{c}\mathbf{0 . 3 0 \%} \\
(0.19 \%- \\
0.46 \%)\end{array}$ & $\begin{array}{c}1.25 \% \\
(0.68 \%- \\
2.29 \%)\end{array}$ & $\begin{array}{c}\mathbf{2 . 3 9 \%} \\
(0.84 \%-6.58 \%)\end{array}$ & $\begin{array}{c}\mathbf{0 . 4 1 \%} \\
(0.22 \%- \\
0.76 \%)\end{array}$ & $\begin{array}{c}3.20 \% \\
(2.27 \%- \\
4.48 \%)\end{array}$ & $\begin{array}{c}1.44 \% \\
(1.16 \%- \\
1.79 \%)\end{array}$ & $\begin{array}{c}1.91 \% \\
(1.75 \%- \\
2.08 \%)\end{array}$ \\
\hline Other hallucinogen & $\begin{array}{c}\mathbf{1 . 1 2 \%} \\
(0.97 \%- \\
1.30 \%)\end{array}$ & $\begin{array}{c}\mathbf{0 . 4 2 \%} \\
(0.26 \%- \\
0.69 \%)\end{array}$ & $\begin{array}{c}\mathbf{1 . 5 1 \%} \\
(0.70 \%- \\
3.24 \%)\end{array}$ & $\begin{array}{c}\mathbf{0 . 9 5 \%} \\
(0.13 \%-6.44 \%)\end{array}$ & $\begin{array}{c}\mathbf{0 . 4 8 \%} \\
(0.25 \%- \\
0.92 \%)\end{array}$ & $\begin{array}{c}\mathbf{1 . 7 3} \% \\
(1.11 \%- \\
2.69 \%)\end{array}$ & $\begin{array}{c}\mathbf{0 . 9 0 \%} \\
(0.59 \%- \\
1.36 \%)\end{array}$ & $\begin{array}{c}\mathbf{0 . 9 8 \%} \\
(0.87 \%- \\
1.10 \%)\end{array}$ \\
\hline $\begin{array}{l}\text { Ever used } \\
\text { hallucinogen }\end{array}$ & $\begin{array}{c}19.43 \% \\
(18.61 \%- \\
20.28 \%)\end{array}$ & $\begin{array}{c}7.57 \% \\
(6.82 \%- \\
8.40 \%)\end{array}$ & $\begin{array}{c}\mathbf{1 8 . 8 7 \%} \\
(14.60 \%- \\
24.04 \%)\end{array}$ & $\begin{array}{c}\mathbf{1 9 . 8 2 \%} \\
(11.11 \%- \\
32.85 \%)\end{array}$ & $\begin{array}{c}\mathbf{8 . 2 5 \%} \\
(6.75 \%- \\
10.06 \%)\end{array}$ & $\begin{array}{c}\mathbf{2 2 . 9 5 \%} \\
(19.08 \%- \\
27.33 \%)\end{array}$ & $\begin{array}{c}10.59 \% \\
(9.66 \%- \\
11.60 \%)\end{array}$ & $\begin{array}{c}\mathbf{1 5 . 9 3 \%} \\
(15.32 \%- \\
16.56 \%)\end{array}$ \\
\hline
\end{tabular}

Note: All groups are non-Hispanic, except "Hispanic American", which is Hispanic of any race. All groups are mutually exclusive. AMT $=\alpha$-Methyltryptamine; DMT $=$ N,N-Dimethyltryptamine; FOXY $=5$-Methoxy-diisopropyltryptamine; LSD $=$ Lysergic acid diethylamide; MDMA = 3,4-Methyl enedioxy methamphetamine; $N=$ Total number of people in each ethnoracial group.

(16.7\%), and multi-racial individuals $(33.8 \%)$, the $26-34$ year olds were the most experienced, although these numbers varied widely. For Asian Americans, the 18-25 range was most experienced $(11.8 \%)$, and for Pacific Islanders, the 50+ range was most experienced (29.4\%). Among all groups, 12-17 year olds were the least experienced. These findings indicate that overall, young adults are experimenting with hallucinogens at higher rates than older cohorts.

\section{DISCUSSION}

This study was designed to examine hallucinogen use among the U.S. population by age group through an ethnoracial lens. Analysis of 2018 NSDUH data (56,313 non-institutionalized participants, weighted to $N=273,753,043$ ) has confirmed unique trends in use among various age cohorts and ethnoracial groupings. This information can be helpful for harm reduction services in identifying groups most in need of intervention and is clinically relevant to researchers working with psychedelic medicine. Further, findings should encourage the reconsideration of many stereotypical beliefs about Black and Hispanic Americans.

\section{Effects of racialization on use of psychedelics}

While nearly $16 \%$ of the population sample had reported hallucinogen use in their lifetime (Table 1 ), only $2 \%$ had reported hallucinogen use within the past year. Within this, we find significant differences between racial groups in regard to hallucinogen use. Non-Hispanic multi-racial persons reported significantly higher than average use, as did Pacific Islander and Native American groups, although the size of the groups precluded verification of significance. Black American individuals reported significantly lower than 


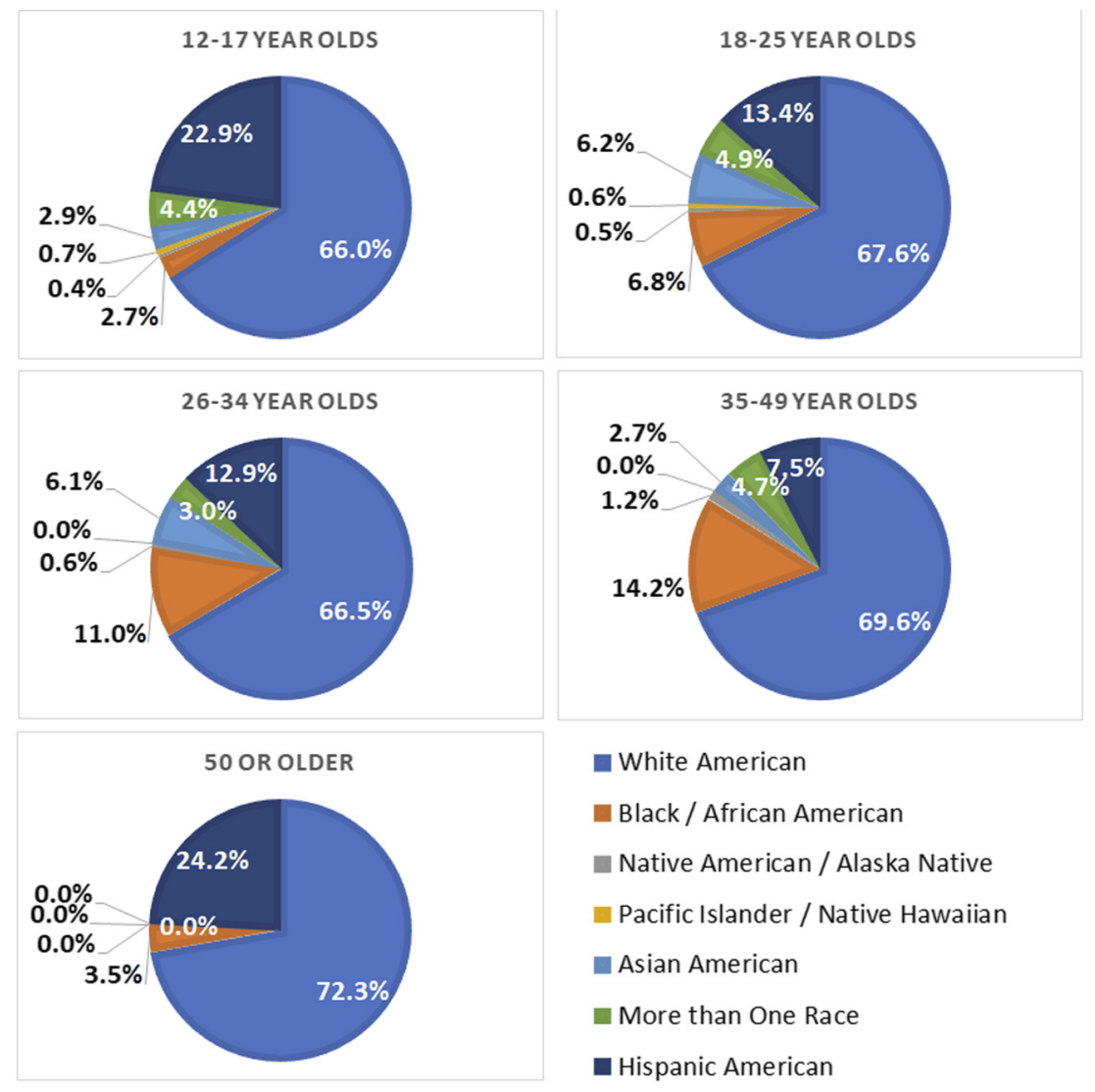

Fig. 2. Users of hallucinogens in the past year, divided by ethnoracial group within each age cohort

average use. In comparing combined categories, use among POC (e.g., Hispanic, Asian, Black) as a group compared with White Americans, most POC are found to use hallucinogens at a lower rate than Non-Hispanic Whites and the general population. Looking at each of these trends separately allows us new insights into the use of psychedelics in these racialized groups.

Inasmuch as there continue to exist marked ethnoracial disparities that negatively affect social outcomes resulting from hallucinogen use, such differences could be expected. In particular, some of the most significant factors connected with drug use that intersect with race include (but are not limited to) in-group socialization, criminalization, and health. In regards to criminalization associated with illicit drug use, individuals in the U.S. with a darker skin complexion are more likely to be racially profiled and searched (White, 2015), furthermore, the current criminal justice system disproportionately charges people in Hispanic and Black groups for narcotic-related crimes at a higher rate than White Americans (Alexander, 2010; Banks, 2003; Beckett et al., 2006). These differences may be expected to affect cultural attitudes and use of drugs including hallucinogens in a race-specific way (e.g., Williams, 2021).

It is noteworthy that Black racialized individuals use hallucinogens at a lower rate than Non-Hispanic Whites and the general population. It remains clear that Black Americans experience greater criminalization and incarceration for drug use of any kind (Alexander, 2010). Faced with this discrepancy, the question that might be asked is if it is more the fear of consequences and cultural in-group stigma that deters Black people from using psychedelics, or rather a desire to conceal drug use from the tester which leads to these results in these groups. Given the literature showing that Blacks have a cultural propensity towards a significantly lower initial risk of substance use disorders compared to White individuals, the former is more likely (Kessler et al., 2005; Abbott \& Chase, 2008).

Underscoring the finding that hallucinogen use is lower in Blacks than any other group included in this study, previous studies have found that despite having a greater proportion of African ancestry (and darker skin, i.e. increased targeting) than U.S.-identifying Blacks, the sub-category of foreign-born Caribbean Blacks (1.7 mio individuals, $4.2 \%$ of US Blacks) have even lower rates of substance use than African Americans (Ben Torres et al., 2008). This could be due to assimilative stress and poorer conditions of African Americans living in the U.S. Following immigration to the U.S., Blacks are subject to higher rates of continuous racism and poverty, and greater societal racialization stress and higher substance use rates by the second generation (Assari, Mistry, \& Caldwell, 2018; Broman et al., 2008). For these Caribbean Blacks, it can be hypothesized that loss of affirming socialization in their home environment, which equates with longer residency in the U.S., correlates with higher instances of drug use (Lacey et al., 2016). Differences 
Table 2. Percent ( $\pm 95 \%$ C.I.) past year hallucinogen use by race/ethnicity and age cohort (weighted)

\begin{tabular}{|c|c|c|c|c|c|c|c|}
\hline Race/age cohort & & 12-17 Years old & 18-25 Years old & 26-34 Years old & 35-49 Years old & $\begin{array}{l}50 \text { Years or } \\
\text { older }\end{array}$ & All \\
\hline \multirow[t]{3}{*}{ White American } & $\%$ & $1.82 \%$ & $8.46 \%$ & $5.10 \%$ & $1.60 \%$ & $0.32 \%$ & $2.19 \%$ \\
\hline & & $(1.45 \%-2.29 \%)$ & $(7.60 \%-9.40 \%)$ & $(4.26 \%-6.10 \%)$ & $(1.23 \%-2.09 \%)$ & $(0.19 \%-0.52 \%)$ & $(1.98 \%-2.44 \%)$ \\
\hline & $N$ & 236,190 & $1,545,303$ & $1,134,135$ & 572,484 & 258,967 & $3,747,078$ \\
\hline \multirow{3}{*}{$\begin{array}{c}\text { Black/African } \\
\text { American }\end{array}$} & $\%$ & $0.29 \%$ & $3.28 \%$ & $3.50 \%$ & $1.56 \%$ & $0.11 \%$ & $1.47 \%$ \\
\hline & & $(0.11 \%-0.78 \%)$ & $(2.40 \%-4.48 \%)$ & $(2.37 \%-5.15 \%)$ & $(0.86 \%-2.84 \%)$ & $(0.02 \%-0.57 \%)$ & $(1.17 \%-1.84 \%)$ \\
\hline & $N$ & 9,763 & 155,393 & 188,450 & 117,081 & 12,604 & 483,290 \\
\hline \multirow{3}{*}{$\begin{array}{c}\text { Native American/ } \\
\text { Alaska Native }\end{array}$} & $\%$ & $0.86 \%$ & $5.64 \%$ & $3.78 \%$ & $2.96 \%$ & $0.00 \%$ & $2.08 \%$ \\
\hline & & $(0.23 \%-3.20 \%)$ & $(1.84 \%-16.01 \%)$ & $(0.88 \%-14.88 \%)$ & $(1.01 \%-8.32 \%)$ & & $(1.11 \%-3.87 \%)$ \\
\hline & $N$ & 1,385 & 12,566 & 9,376 & 10,206 & 0 & 33,532 \\
\hline \multirow{3}{*}{$\begin{array}{l}\text { Pacific Islander/ } \\
\text { Native Hawaiian }\end{array}$} & $\%$ & $2.38 \%$ & $9.17 \%$ & $0.00 \%$ & $0.00 \%$ & $0.00 \%$ & $1.66 \%$ \\
\hline & & $(0.36 \%-13.99 \%)$ & $(2.34 \%-29.82 \%)$ & & & & $(0.63 \%-4.29 \%)$ \\
\hline & $N$ & 2,456 & 14,550 & 0 & 0 & 0 & 17,006 \\
\hline \multirow[t]{3}{*}{ Asian American } & $\%$ & $0.72 \%$ & $6.18 \%$ & $3.44 \%$ & $0.49 \%$ & $0.00 \%$ & $1.78 \%$ \\
\hline & & $(0.28 \%-1.83 \%)$ & $(4.11 \%-9.20 \%)$ & $(2.11 \%-5.55 \%)$ & $(0.20 \%-1.19 \%)$ & & $(1.32 \%-2.39 \%)$ \\
\hline & $N$ & 10,304 & 140,774 & 104,313 & 21,935 & 0 & 277,327 \\
\hline \multirow[t]{3}{*}{ More than one race } & $\%$ & $1.97 \%$ & $15.00 \%$ & $7.21 \%$ & $5.04 \%$ & $0.00 \%$ & $4.14 \%$ \\
\hline & & $(1.15 \%-3.36 \%)$ & $(10.68 \%-20.66 \%)$ & $(4.09 \%-12.39 \%)$ & $(1.98 \%-12.22 \%)$ & & $(3.01 \%-5.67 \%)$ \\
\hline & $N$ & 15,608 & 112,138 & 50,503 & 38,938 & 0 & 217,186 \\
\hline \multirow[t]{3}{*}{ Hispanic American } & $\%$ & $1.35 \%$ & $4.01 \%$ & $2.66 \%$ & $0.51 \%$ & $0.69 \%$ & $1.62 \%$ \\
\hline & & $(0.89 \%-2.03 \%)$ & $(3.08 \%-5.21 \%)$ & $(1.71 \%-4.12 \%)$ & $(0.26 \%-0.98 \%)$ & $(0.26 \%-1.86 \%)$ & $(1.28 \%-2.06 \%)$ \\
\hline & $N$ & 82,097 & 305,577 & 219,437 & 61,622 & 86,752 & 755,485 \\
\hline \multirow{3}{*}{$\begin{array}{l}\text { Past year } \\
\text { hallucinogen use }\end{array}$} & $\%$ & $1.44 \%$ & $6.72 \%$ & $4.26 \%$ & $1.34 \%$ & $0.32 \%$ & $2.02 \%$ \\
\hline & & $(1.21 \%-1.71 \%)$ & $(6.13 \%-7.36 \%)$ & $(3.65 \%-4.97 \%)$ & $(1.07 \%-1.68 \%)$ & $(0.20 \%-0.49 \%)$ & $(1.84 \%-2.21 \%)$ \\
\hline & $N$ & 357,802 & $2,286,300$ & $1,706,214$ & 822,265 & 358,323 & $5,530,903$ \\
\hline
\end{tabular}

$N=$ Number of people in each ethnoracial group and age cohort who had reported using a hallucinogenic substance in the past year; Row percentages represent the number of past year hallucinogen users by age cohort, within each ethnoracial group separately.

found between these two Black groups again point toward internal validity in regards to self-reporting as it is not likely that self-reporting would vary within a racial clade. The lower-than-average-use findings are furthermore consistent with other literature that indicates that the $98 \%$ of U.S. Blacks not incarcerated (incarcerated are excluded from this study) are socialized to avoid hallucinogens and the disproportionate punishment that the law brings with their possession.

Pacific Islanders and Native Americans represent 0.2\% and $1.3 \%$ of the U.S. population, respectively, which is approximately 5 million people (United States Census Bureau, 2019). Due to small sample sizes and large margins of error within these groups, limited conclusions can be drawn. However, the proportions of reported lifetime hallucinogen use were slightly elevated in comparison to the general population, unlike the statistics of most other POC. While there are likely many factors that contribute to this finding (e.g., illicit substance abuse is more prevalent in these populations; Young \& Joe, 2009), considerations surrounding cultural views on hallucinogen use for healing purposes are pivotal to understanding these results. This coincides with the results of previous national data analysis indicating that Native Hawaiian and other Pacific Islanders use some substances (i.e., non-medical marijuana and opioid analgesics) at rates higher than White, non-Hispanic Americans (Wu, Woody, Yang, Pan, \& Blazer, 2011). Members of the Native American
Church utilize substances such as the mescaline containing Peyote cactus as sacrament in traditional ceremonial practice for its healing properties, both physical and spiritual (Jones, 2007). Rates of peyote use were notably higher in the Native American group, which is unsurprising given that there are 250,000 members in the Native American Church. Rates of use for all other hallucinogens were lower or comparable to White Americans. Further study is necessary to understand the impact that this practice has on overall cultural acceptability of hallucinogen use.

This evidence presented here should serve to dampen any existing stereotypes that label POC as more frequent users of hallucinogens and other illicit dissociative drugs, although previous work has also confirmed that POC exhibit lower rates of substance use and abuse (Gibbs et al., 2013; Mericle, Park, Holck, \& Arria, 2012). In combination, the data presented here provides a fuller picture which is contrary to existing biases.

The only racialized group that had consistently higher rates of hallucinogen use (compared to the average) were non-Hispanic multi-racial individuals, who comprise $2.8 \%$ of the U.S. population. Their lifetime and past year use were significantly greater than other POC groups, and their rates of use were highest for every type of substance and in every age category, except for those over 50 years old. Rates of use among multi-racial Americans were similar to use among White Americans. 
Table 3. Percent ( $\pm 95 \%$ C.I.) Lifetime Hallucinogen Use by Race/Ethnicity and Age Cohort (weighted)

\begin{tabular}{|c|c|c|c|c|c|c|c|}
\hline Race/age cohort & & $\begin{array}{c}\text { 12-17 Years } \\
\text { old }\end{array}$ & $\begin{array}{c}18-25 \text { Years } \\
\text { old }\end{array}$ & $\begin{array}{c}\text { 26-34 Years } \\
\text { old }\end{array}$ & $\begin{array}{c}\text { 35-49 Years } \\
\text { old }\end{array}$ & $\begin{array}{l}50 \text { Years or } \\
\text { older }\end{array}$ & All \\
\hline \multirow[t]{3}{*}{ White American } & $\%$ & $2.53 \%$ & $19.86 \%$ & $28.68 \%$ & $26.88 \%$ & $16.24 \%$ & $19.43 \%$ \\
\hline & & $\begin{array}{c}(2.01 \%- \\
3.19 \%)\end{array}$ & $\begin{array}{c}(18.51 \%- \\
21.29 \%)\end{array}$ & $\begin{array}{c}(26.78 \%- \\
30.67 \%)\end{array}$ & $\begin{array}{l}(25.37 \%- \\
28.43 \%)\end{array}$ & $\begin{array}{c}(14.99 \%- \\
17.57 \%)\end{array}$ & $\begin{array}{c}(18.61 \%- \\
20.28 \%)\end{array}$ \\
\hline & $N$ & 328,215 & $3,629,345$ & $6,374,687$ & $9,591,399$ & $13,250,134$ & $33,173,781$ \\
\hline \multirow[t]{3}{*}{ Black/African American } & $\%$ & $0.78 \%$ & $7.00 \%$ & $11.66 \%$ & $8.80 \%$ & $7.10 \%$ & $7.57 \%$ \\
\hline & & $\begin{array}{c}(0.47 \%- \\
1.31 \%)\end{array}$ & $(5.88 \%-8.33 \%)$ & $\begin{array}{l}(9.67 \%- \\
13.99 \%)\end{array}$ & $\begin{array}{l}(7.14 \%- \\
10.80 \%)\end{array}$ & $(5.51 \%-9.11 \%)$ & $(6.82 \%-8.40 \%)$ \\
\hline & $N$ & 26,371 & 331,479 & 627,637 & 659,081 & 850,018 & $2,494,586$ \\
\hline \multirow{3}{*}{$\begin{array}{l}\text { Native American/Alaska } \\
\text { Native }\end{array}$} & $\%$ & $3.95 \%$ & $19.74 \%$ & $36.51 \%$ & $33.24 \%$ & $7.63 \%$ & $18.87 \%$ \\
\hline & & $\begin{array}{l}(1.48 \%- \\
10.16 \%)\end{array}$ & $\begin{array}{c}(13.30 \%- \\
28.29 \%)\end{array}$ & $\begin{array}{c}(25.79 \%- \\
48.74 \%)\end{array}$ & $\begin{array}{c}(25.92 \%- \\
41.46 \%)\end{array}$ & $\begin{array}{l}(3.26 \%- \\
16.84 \%)\end{array}$ & $\begin{array}{c}(14.60 \%- \\
24.04 \%)\end{array}$ \\
\hline & $N$ & 6,391 & 43,960 & 90,547 & 114,720 & 48,312 & 303,930 \\
\hline \multirow{3}{*}{$\begin{array}{l}\text { Pacific Islander/Native } \\
\text { Hawaiian }\end{array}$} & $\%$ & $2.38 \%$ & $23.86 \%$ & $21.72 \%$ & $12.11 \%$ & $29.37 \%$ & $19.82 \%$ \\
\hline & & $\begin{array}{l}(0.36 \%- \\
13.99 \%)\end{array}$ & $\begin{array}{c}(10.96 \%- \\
44.38 \%)\end{array}$ & $\begin{array}{c}(10.80 \%- \\
38.85 \%)\end{array}$ & $\begin{array}{l}(3.49 \%- \\
34.43 \%)\end{array}$ & $\begin{array}{l}(8.81 \%- \\
64.16 \%)\end{array}$ & $\begin{array}{l}(11.11 \%- \\
32.85 \%)\end{array}$ \\
\hline & $N$ & 2,456 & 37,855 & 37,655 & 33,647 & 91,408 & 203,022 \\
\hline \multirow[t]{3}{*}{ Asian American } & $\%$ & $1.77 \%$ & $11.75 \%$ & $10.77 \%$ & $6.91 \%$ & $8.18 \%$ & $8.25 \%$ \\
\hline & & $\begin{array}{c}(0.77 \%- \\
4.04 \%)\end{array}$ & $\begin{array}{l}(8.98 \%- \\
15.23 \%)\end{array}$ & $\begin{array}{l}(7.70 \%- \\
14.87 \%)\end{array}$ & $(4.81 \%-9.82 \%)$ & $\begin{array}{l}(4.90 \%- \\
13.35 \%)\end{array}$ & $\begin{array}{l}(6.75 \%- \\
10.06 \%)\end{array}$ \\
\hline & $N$ & 25,341 & 267,683 & 326,750 & 308,939 & 356,835 & $1,285,549$ \\
\hline \multirow[t]{3}{*}{ More than one race } & $\%$ & $2.85 \%$ & $27.71 \%$ & $33.84 \%$ & $33.51 \%$ & $21.39 \%$ & $22.95 \%$ \\
\hline & & $\begin{array}{c}(1.77 \%- \\
4.55 \%)\end{array}$ & $\begin{array}{c}\% \\
(22.64 \%- \\
33.42 \%)\end{array}$ & $\begin{array}{c}(25.80 \%- \\
42.94 \%)\end{array}$ & $\begin{array}{c}(27.09 \%- \\
40.60 \%)\end{array}$ & $\begin{array}{c}(14.19 \%- \\
30.94 \%)\end{array}$ & $\begin{array}{c}(19.08 \%- \\
27.33 \%)\end{array}$ \\
\hline & $N$ & 22,555 & 207,153 & 237,149 & 259,009 & 476,881 & $1,202,748$ \\
\hline \multirow[t]{3}{*}{ Hispanic American } & $\%$ & $1.99 \%$ & $13.26 \%$ & $16.85 \%$ & $11.43 \%$ & $8.20 \%$ & $10.59 \%$ \\
\hline & & $\begin{array}{c}(1.43 \%- \\
2.76 \%)\end{array}$ & $\begin{array}{c}(11.49 \%- \\
15.26 \%)\end{array}$ & $\begin{array}{c}(14.47 \%- \\
19.53 \%)\end{array}$ & $\begin{array}{l}(9.74 \%- \\
13.38 \%)\end{array}$ & $\begin{array}{l}(5.68 \%- \\
11.69 \%)\end{array}$ & $\begin{array}{l}(9.66 \%- \\
11.60 \%)\end{array}$ \\
\hline & $N$ & 121,024 & $1,011,081$ & $1,392,006$ & $1,390,296$ & $1,024,623$ & $4,939,031$ \\
\hline \multirow[t]{3}{*}{ Lifetime hallucinogen use } & $\%$ & $2.14 \%$ & $16.24 \%$ & $22.70 \%$ & $20.19 \%$ & $14.17 \%$ & $15.93 \%$ \\
\hline & & $\begin{array}{c}(1.83 \%- \\
2.49 \%)\end{array}$ & $\begin{array}{c}(15.24 \%- \\
17.29 \%)\end{array}$ & $\begin{array}{c}(21.41 \%- \\
24.05 \%)\end{array}$ & $\begin{array}{c}(19.15 \%- \\
21.27 \%)\end{array}$ & $\begin{array}{c}(13.13 \%- \\
15.28 \%)\end{array}$ & $\begin{array}{c}(15.32 \%- \\
16.56 \%)\end{array}$ \\
\hline & $N$ & 532,354 & $5,528,558$ & $9,086,431$ & $12,357,092$ & $16,098,211$ & $43,602,646$ \\
\hline
\end{tabular}

$N=$ Number of people in each ethnoracial group and age cohort who had reported using a hallucinogenic substance in their lifetime; Row percentages represent the number of lifetime hallucinogen users by age cohort, within each ethnoracial group separately.

\section{Use of psychedelics in youth}

Consistent with the broader literature, we find that younger cohorts are more avid users of psychedelic substances. The highest rates of past year use for nearly all ethnoracial groups were among 18-25 year olds. The only exception to this trend was within the Black/African American group, where the highest rates were reported among the 26-34 year old cohort. This is consistent with previous findings which have demonstrated higher rates of substance use among age cohorts between 18 and 25 years of age (Chilcoat \& Schütz, 1996; Schulenberg et al., 2020) with the pointed exception of Black respondents. This is also consistent with literature which has found lower rates of psychedelic use among Black college students compared to other groups (McCabe et al., 2007).

One of the most prominent examples of the protective effect of ethnoracial identity is observed among African American youth, where higher levels of ethnoracial identity correlate with lower rates of substance use (Richman,
Boynton, Costanzo, \& Banas, 2013). Especially among Black college students, alcohol and drug use are reduced as a result of greater sense of ethnoracial identity and belonging (Pugh \& Bry, 2007). Therefore, individuals with a greater degree of ethnoracial identity generally partake in fewer illegal activities, which protects these individuals from being caught up in the criminal justice system. For this reason, we might expect that those included in this sample ( $98 \%$ of U.S. Blacks) would have a lower rate of hallucinogen use than Whites whose lawlessness/criminality is not as harshly penalized (Beckett et al., 2006). We postulate that this may partially account for the relatively low number of Blacks who have reported hallucinogen use in their lifetime. Additionally, Black families have stricter rules for youth for their protection (Adjei \& Minka, 2018; Cucchiara, 2020), typically in order to mitigate this disproportionate criminal justice response. This would also likely explain why Blacks who have used substances in the past year are more likely to be $26-34$ years of age, rather 
than $18-25$, as is the general trend among the remainder of ethnoracial groups.

Non-Hispanic multi-racial individuals comprise the highest rate of past year users of hallucinogens among 18-25 year olds. While the 2010 census established that multiracial groups grew faster than the single-race population from 2000 to 2010 in the U.S. (US Census Bureau, 2012), this group is also projected as the fastest growing ethnoracial grouping from 2010 to 2020 (Mather et al., 2019). This small but rapidly growing group of multi-racial youth in particular are at a higher risk of substance use in comparison to their more numerous single-race counterparts. Since a strong sense of ethnoracial identity is correlated with higher selfesteem and lower occurrences of substance use in adolescents (Choi, Harachi, Gillmore, \& Catalano, 2006; Fisher, Zapolski, Sheehan, \& Barnes-Najor, 2017), multi-racial individuals are at a disadvantage. Identity development, and any protective components thereof, may be more challenging for this population in comparison to their monoracial counterparts, as multi-racial individuals are tasked with incorporating multiple ethnicities into one classification (Fisher et al., 2017; Gonzales-Backen, 2013).

\section{First use of psychedelics and trends}

The age at first hallucinogen use among recent hallucinogen initiates (aged 12-49) is 19.6 years (Lipari, Ahrnsbrak, Pemberton, \& Porter, 2017). Trends from the NHSDA from 1988 to 1992 also found that the age at which hallucinogen use was most likely to occur was age 19 (Chilcoat \& Schütz, 1996). This age range generally represents transition from adolescence to adulthood, when young adults are first exposed to various licit and illicit substances and can make independent decisions about their behaviors.

There also appears to be an educational divide in hallucinogen use. A 2017 analysis of national survey data found that from 2007 to 2014, those with a college degree used ecstasy at significantly increased rates $(11.5 \%$ in 2007 to $24.5 \%$ in 2013) along with those earning $\$ 20,000-\$ 49,999$ (Palamar, Mauro, Han, \& Martins, 2017). This finding further demonstrates elevated instances of hallucinogen use during transitional periods in life; as such, age-related patterns of hallucinogen use have remained stable since these substances became widely available during the late 1960s (Chilcoat \& Schütz, 1996). Shalit et al. (2019) also found that hallucinogen users were more likely to have a higher level of education.

We did not find that older cohorts were using more hallucinogens. On the contrary, they had the lowest past year use. This may be due to the stigmatization of hallucinogens over the course of the War on Drugs, which is relevant for the avoidance of use among older age cohorts (Shalit et al., 2019). Hallucinogens such as MDMA have been slowly gaining notoriety from large media outlets as pharmaceutical substances that have clinically proven, legitimated spectrum of use (Mithoefer et al., 2019; Ot'alora et al., 2018). In addition, generational loosening of attitudes towards use of drugs have likely contributed to the effect of increased use among younger cohorts. This nearing legitimacy has resulted in the decriminalization of many psychedelic substances in various states. However, there hasn't been any widespread reduction in legal or social consequences for racialized minorities in particular.

The anomaly that the Black respondents are initiating psychedelics at a significantly older age than average and also at an older age than White cohorts is also interesting, because it serves as an internal control for the anomalous trend highlighted above: Black groups generally use hallucinogens at a reduced rate. If the reason for the late initiation of hallucinogen use by Black youth is Black cultural norms, and not a desire to hide their response from the rater, then we would expect to see a late initiation of hallucinogen use, as is consistent with the results (Jones et al., 2020). If the respondents are answering in the affirmative that yes, they have used hallucinogens, it seems unlikely that the younger cohorts within the Black respondents are acting differently (responding untruthfully) more so than the older cohorts.

We also see differences between racialized groups in lifetime vs. recent (past year) use. Overall, $2.0 \%$ of participants responded that they had used hallucinogens in the past year, while $15.9 \%$ had used hallucinogens in their lifetime (see Tables 2 and 3). It is notable that African Americans reported the lowest percentage of users among all groups, with $1.5 \%$ of African American participants reporting past year use, and $7.6 \%$ of them reporting any lifetime use at all. In both cases, these numbers were statistically much lower than the aforementioned national overall rates of past year use $(2.0 \%)$ and the rates of lifetime use (15.9\%). This is consistent with our findings that African American groups are among the lowest, if not the lowest, users of hallucinogens in the United States as of 2018. On the other hand, highest rates of use were among multi-racial groups for both lifetime use $(23.0 \%)$ and past year use (4.1\%) (see Tables 2 and 3 ).

In terms of differences between lifetime versus past year analyses by age and race, we see that the older generation has tried their fair share of hallucinogens, relatively speaking, but are not continuing to use them based on past year figures. This could be due to previous exposure to the psychedelic boom of the mid-20th century which has since died down; perhaps older populations are more likely to now stigmatize these substances, as they have lived through the initiation of the War on Drugs.

\section{Health reasons for psychedelics use}

POC may use substances to cope with the sequelae of racial trauma, especially if they do not have access to empiricallysupported treatments or when those treatments are not effective. Although many substances can exacerbate existing mental health problems, the use of psychedelics has been associated with reduction in psychological distress (Johansen \& Krebs, 2015), and many people report lasting benefits. Williams et al. (2021) found that naturalistic use of psychedelics in some people of color was associated with reduction in stress, anxiety, and depression caused by experiences of discrimination. Hallucinogen use is also associated with other 
substance use and psychiatric disorders (Shalit et al., 2019). This suggests that some may already use hallucinogens to selfmedicate, as many people use psychedelics for coping, particularly females (Kettner, Mason, \& Kuypers, 2019). Beyond naturalistic use of psychedelics, studies conducted in the last decade have demonstrated that psychedelics are particularly effective in treating disorders when paired with psychotherapy in a clinical setting, such as PTSD (Mithoefer et al., 2019), depression (Davis et al., 2020), end-of-life anxiety (Griffiths et al., 2016), and substance use disorders (Johnson et al., 2014; Sessa et al., 2021). Most notably, the FDA designated MDMA-assisted psychotherapy a breakthrough therapy for treatment-resistant PTSD (Burns, 2017), and the same designation was granted to psilocybin-assisted psychotherapy in the treatment of major depressive disorder (Patterson, 2019).

As localities begin to decriminalize various governmentally illicit substances of abuse, it is foreseeable that there will be an increased amount of funding allocated toward harm reduction programs (Drug Policy Alliance, 2017). Psychoeducation, rehabilitation, and safe-spaces are a few types of programs that will benefit from the impact of the decriminalization of various substances (Virani \& Haines-Saah, 2019). Since non-Hispanic, multi-racial groups within the 18-25 age cohort reported the highest rates of past year use among all ethnoracial backgrounds and age groups (15\%), this group should be prioritized for harm-reduction and educational programs when considering the potential hazards of illicit hallucinogen use. As multi-racial individuals are less likely to have a strong, positive ethnoracial identity as a buffer for various pathological symptoms, including problematic substance use, this is a potential target for interventions (Choi et al., 2006).

\section{LIMITATIONS}

While this work has many strengths, including the use of a large sample size representative of the general U.S. population, as well as the inclusion of seven ethnoracial groups and five age cohorts, there are certain key limitations which must be addressed. First, the concept of 'race' is a social construct (Tate \& Audette, 2001), and is therefore vulnerable to changes in classifications over time. This is a notable limitation when attempting to compare hallucinogen use statistics longitudinally, as the U.S. census classifications change nearly every decade (Hirschman, Alba, \& Farley, 2000). Furthermore, an individual's ethnoracial classification is subject to change as well, given that people may selfidentify differently over time and depending on evolving social contexts (Liebler, Porter, Fernandez, Noon, \& Ennis, 2017), particularly multi-racial individuals. For example, the 2019 census estimates that there are 40.8 million African Americans and about 6.1 total million mixed race population in the U.S. (Black-Hispanic and Black-White), and some of the mixed race individuals identify as Black while some do not (Tamir, 2021). However, at this time this is likely to represent only a minor issue, as evolving racial categorization changes the total size of racialized groups by amounts that do not influence the general finding.

Although this data excludes institutionalized persons, who may be disproportionately using hallucinogens, the incarcerated and institutionalized represent only a fraction of the population. Of those incarcerated, about a fifth $(450,000)$ are confined for drug use (Sawyer \& Wagner, 2020). In the instance of persons racialized as Black, the incarcerated represent up to $40 \%$ of the total of the 2.3 million incarcerated persons in the U.S.; this is approximately 920,000 individuals who represent a small portion (2\%) of the total 46 million Black Americans. Since the incarcerated and institutionalized also generally have limited access to drugs, their exclusion from this data does not invalidate its relevance.

The overgeneralization of the Hispanic ethnoracial category in the SAMHSA data report is a further limitation to this study. Although the NSDUH questionnaire asked participants whether to indicate their race/ethnicity as Hispanic or Non-Hispanic, there was no data available to show intersectional identity such as Hispanic White or NonHispanic White (SAMHSA, 2018). There will be notable differences between these two groups and their experiences of racism, so homogeneity should not be assumed (Uhlmann, 2002; Hunter, 2015). Finally, we did not examine gender differences, which is certainly another interesting and important avenue for further research.

The survey method used by SAMHSA has further limitations. Firstly, the data is self-reported, which may be affected by a participant's memory and willingness to provide truthful responses. While the ACASI interview method may improve privacy and confidentiality, the presence of an interviewer and the sensitive nature of drug use and mental illness may affect the data reliability (i.e., under- or overreporting). Secondly, the data collection is cross-sectional; individuals are interviewed only once and are not tracked over time. Longitudinal data would provide detailed information on how certain patterns of drug use and/or mental illnesses change over time on an individual level vs. a snapshot in time for the population.

\section{CONCLUSIONS}

Findings from this work demonstrate that trends in hallucinogen use in the United States differ from perceived stereotypes, and the results provide a current assessment of past year and lifetime prevalence in use among various ethnoracial and age groups. Given the rise in popularity and acceptance of psychedelics in the general population, it is essential to understand and quantify which groups are already using these substances. Importantly, this data also sheds light on which groups are not currently using hallucinogens, which could play a role in their future use for the treatment of mental health and substance use disorders. While additional work is needed, results from this study may inform current and future culturally-diverse substance use interventions and therapeutic psychedelic research. 


\section{ACKNOWLEDGMENTS}

This research was undertaken, in part, thanks to funding from the Canada Research Chairs Program (M. Williams, award number: 950-232127).

\section{REFERENCES}

Abbott, P., \& Chase, D. M. (2008). Culture and substance abuse: Impact of culture affects approach to treatment. Psychiatric Times, 25(1).

Abdel-Azeem, A., Abdel-Azeem, M., \& Blanchette, R. (2016, October 18-20). The Conservation of Mushroom in ancient Egypt through the present [conference presentation]. The First International Conference on Fungal Conservation in the Middle East and North of Africa. Ismailia, Egypt.

Adjei, P. B., \& Minka, E. (2018). Black parents ask for a second look: Parenting under 'White' Child Protection rules in Canada. Children and Youth Services Review, 94, 511-524. https://doi. org/10.1016/j.childyouth.2018.08.030.

Alexander, M. (2010). The new Jim Crow: Mass incarceration in the age of colorblindness. New Press.

Assari, S., Mistry, R., \& Caldwell, C. H. (2018). Perceived discrimination and substance use among Caribbean black youth; gender differences. Brain Sciences, 8(7), 131. https://doi. org/10.3390/brainsci8070131.

Banks, R. R. (2003). Beyond profiling: Race, policing, and the drug war. Stanford Law Review, 56(3), 571-603. https://doi.org/10. 2139/ssrn.478481.

Beckett, K., Nyrop, K., \& Pfingst, L. (2006). Race, drugs, and policing: Understanding disparities in drug delivery arrests. Criminology, 44(1), 105-137. https://doi:10.1111/j.1745-9125.2006.00044.x.

Benn-Torres, J., Bonilla, C., Robbins, C. M., Waterman, L., Moses, T. Y., Hernandez, W., et al. (2008). Admixture and population stratification in African Caribbean populations. Annals of $\mathrm{Hu}$ man Genetics, 72(Pt 1), 90-98. https://doi.org/10.1111/j.14691809.2007.00398.x.

Broman, C. L., Neighbors, H. W., Delva, J., Torres, M., \& Jackson, J. S. (2008). Prevalence of substance use disorders among African Americans and Caribbean Blacks in the National Survey of American Life. American Journal of Public Health, 98, 1107-1114. https://doi.org/10.2105/AJPH.2006.100727.

Burns, J. (2017, August 28). FDA Designates MDMA As "Breakthrough Therapy" For Post-Traumatic Stress. Forbes. https:// www.forbes.com/sites/janetwburns/2017/08/28/fda-designatesmdma-as-breakthrough-therapy-for-post-traumatic-stress/.

Carhart-Harris, R. L., Bolstridge, M., Rucker, J., Day, C. M., Erritzoe, D., Kaelen, M., et al. (2016). Psilocybin with psychological support for treatment-resistant depression: An open-label feasibility study. Lancet Psychiatry, 3(7), 619-627. https:// doi.org/10.1016/S2215-0366(16)30065-7.

Center for Behavioral Health Statistics and Quality. (2015). National survey on drug use and health: 2014 and 2015 redesign changes. Substance Abuse and Mental Health Services Administration, Rockville, MD.
Center for Behavioral Health Statistics and Quality. (2019). 2018 national survey on drug use and health: Methodological resource book (section 2, sample design report). Substance Abuse and Mental Health Services Administration, Rockville, MD.

Chilcoat, H. D., \& Schütz, C. G. (1996). Age-specific patterns of hallucinogen use in the US population: An analysis using generalized additive models. Drug and Alcohol Dependence, 43(3), 143-153. https://doi.org/10.1016/s0376-8716(96)01297-5.

Choi, Y., Harachi, T. W., Gillmore, M. R., \& Catalano, R. F. (2006). Are multiracial adolescents at greater risk? Comparisons of rates, patterns, and correlates of substance use and violence between monoracial and multiracial adolescents. American Journal of Orthopsychiatry, 76(1), 86-97. https://doi.org/10. 1037/0002-9432.76.1.86.

Chou, R. S., \& Feagin, J. R. (2015). Myth of the model minority: Asian Americans facing racism. Routledge.

Cucchiara, M. (2020). "Sometimes you have to pop them": Conflict and meaning-making in a parenting class. Social Problems, spaa045. https://doi.org/10.1093/socpro/spaa045.

Davis, A. K., Barrett, F. S., May, D. G., Cosimano, M. P., Sepeda, N. D., Johnson, M. W., et al. (2020). Effects of psilocybin-assisted therapy on major depressive disorder: A randomized clinical trial. JAMA Psychiatry, e203285. Advance online publication. https://doi.org/10.1001/jamapsychiatry.2020.3285.

Drug Policy Alliance (2017). It's time for the U.S. to decriminalize drug use and possession. A Drug Policy Alliance Release. https:// drugpolicy.org/sites/default/files/documents/Drug_Policy_ Alliance_Time_to_Decriminalize_Report_July_2017.pdf.

Dyck, E. (2016). Peyote and psychedelics on the Canadian prairies. In B. C. Labate, \& C. Cavnar (Eds.), Peyote: History, tradition, politics, and conservation (pp. 151-170). Praeger/ABC-CLIO.

Fisher, S., Zapolski, T. C. B., Sheehan, C., \& Barnes-Najor, J. (2017). Pathway of protection: Ethnic identity, self-esteem, and substance use among multiracial youth. Addictive Behaviors, 72, 27-32. https://doi.org/10.1016/j.addbeh.2017.03.003.

Gibbs, T. A., Okuda, M., Oquendo, M. A., Lawson, W. B., Wang, S., Thomas, Y. F., et al. (2013). Mental health of African Americans and Caribbean Blacks in the United States: Results from the national epidemiological survey on alcohol and related conditions. American Journal of Public Health (1971), 103(2), 330-338. https://doi.org/10.2105/ajph.2012.300891.

Gonzales-Backen, M. A. (2013). An application of ecological theory to ethnic identity formation among biethnic adolescents. Family Relations, 62(1), 92-108. https://doi.org/10.1111/j.17413729.2012.00749.x.

Griffiths, R. R., Johnson, M. W., Carducci, M. A., Umbricht, A., Richards, W. A., Richards, B. D., et al. (2016). Psilocybin produces substantial and sustained decreases in depression and anxiety in patients with life-threatening cancer: A randomized double-blind trial. Journal of Psychopharmacology, 30(12), 1181-1197. https://doi.org/10.1177/0269881116675513.

Hall, M. F. (1997). The "war on drugs": A continuation of the war on the African American family. Smith College Studies in Social Work, 67(3), 609-621. https://doi.org/10.1080/ 00377319709517509.

Hirschman, C., Alba, R., \& Farley, R. (2000). The meaning and measurement of race in the U.S. Census: Glimpses into the future. Demography, 37(3), 381-393. https://doi.org/10.2307/2648049. 
Hunter, M. (2015). Colorism in the classroom: How skin tone stratifies African American and Latina/o students. Theory Into Practice, 55(1), 54-61. https://doi.org/10.1080/00405841.2016. 1119019.

Jay, M. (2019). Mescaline: A global history of the first psychedelic. New Haven: Yale University Press.

Johansen, P. -Ø., \& Krebs, T. S. (2015). Psychedelics not linked to mental health problems or suicidal behavior: A population study. Journal of Psychopharmacology, 29(3), 270-279. https:// doi.org/10.1177/0269881114568039.

Johnson, M. W., Garcia-Romeu, A., Cosimano, M. P., \& Griffiths, R. R. (2014). Pilot study of the 5-HT2AR agonist psilocybin in the treatment of Tobacco addiction. Journal of Psychopharmacology, 28(11), 983-992.

Jones, P. N. (2007). The native American Church, peyote, and health: Expanding consciousness for healing purposes. Contemporary Justice Review: CJR, 10(4), 411-425. https://doi. org/10.1080/10282580701677477.

Jones, C. M., Clayton, H. B., Deputy, N. P., Roehler, D. R., Ko, J. Y., Esser, M. B., et al. (2020). Prescription opioid misuse and use of alcohol and other substances among high school students Youth risk behavior survey, United States, 2019. Morbidity and Mortality Weekly Report Supplements, 69(1), 38-46.

Kessler, R. C., Berglund, P., Demler, O., Jin, R., Merikangas, K. R., \& Walters, E. E. (2005). Lifetime prevalence and age-of-onset distributions of DSM-IV disorders in the national comorbidity survey replication. Archives of General Psychiatry, 62(6), 593602. https://doi.org/10.1001/archpsyc.62.6.593.

Kettner, H., Mason, N. L., \& Kuypers, K. P. C. (2019). Motives for classical and novel psychoactive substances use in psychedelic polydrug users. Contemporary Drug Problems, 46(3), 304-320. https://doi.org/10.1177/0091450919863899.

Klein, C. F., Guzmán, E., Mandell, E. C., Stanfield-Mazzi, M, Baudez, C.-F., Brown, J. A., et al. (2002). The role of shamanism in Mesoamerican art: A reassessment. Current Anthropology, 43(3), 383-419. https://doi.org/10.1086/339529.

Krebs, T. S., \& Johansen, P. (2013). Over 30 million psychedelic users in the United States. F1000 Research, 2, 98.

Kristinsson, J. (2008). Occurrence and use of hallucinogenic mushrooms containing psilocybin alkaloids. Nordic Counsil of Ministers.

Labate, B. C., \& Cavnar, C. (Eds.). (2016). Peyote: history, tradition, politics, and conservation. ABC-CLIO.

Lacey, K. K., Mouzon, D. M., Govia, I. O., Matusko, N., ForsytheBrown, I., Abelson, J. M., et al. (2016). Substance abuse among blacks across the diaspora. Substance Use \& Misuse, 51(9), 1147-1158. https://doi.org/10.3109/10826084.2016.1160124.

Liebler, C. A., Porter, S. R., Fernandez, L. E., Noon, J. M., \& Ennis, S. R. (2017). America's churning races: Race and ethnicity response changes between census 2000 and the 2010 census. Demography, 54(1), 259-284. https://doi.org/10.1007/s13524016-0544.

Lipari, R. N., Ahrnsbrak, R. D., Pemberton, M. R., \& Porter, J. D. (2017). Risk and protective factors and estimates of substance use initiation: Results from the 2016 national survey on drug use and health. In CBHSQ data review. (pp. 1-32). Substance Abuse and Mental Health Services Administration (US).
Lloyd, S. L., \& Striley, C. W. (2018). Marijuana use among adults 50 years or older in the 21st century. Gerontology \& Geriatric Medicine, 4. https://doi.org/10.1177/2333721418781668.

Luoma, J. B., Chwyl, C., Bathje, G. J., Davis, A. K., \& Lancelotta, R. (2020). A meta-analysis of placebo-controlled trials of psychedelic-assisted therapy. Journal of Psychoactive Drugs, 52(4), 289-299. https://doi.org/10.1080/02791072.2020.1769878.

Mather, M., Jacobsen, L. A., Jarosz, B., Kilduff, L., Lee, A., Pollard, K. M., et al. (2019). America's changing population: What to expect in the 2020 census. Population Bulletin, 74(1), 0_1-21. http://hispanicad.com/sites/default/files/prb-popbulletin-2020census-compressed.pdf.

McCabe, S. E., Morales, M., Cranford, J. A., Delva, J., McPherson, M. D., \& Boyd, C. J. (2007). Race/ethnicity and gender differences in drug use and abuse among college students. Journal of Ethnicity in Substance Abuse, 6(2), 75-95. https://doi.org/10. 1300/J233v06n02_06.

Mericle, A. A., Park, V. M. T., Holck, P., \& Arria, A. M. (2012). Prevalence, patterns, and correlates of co-occurring substance use and mental disorders in the United States: Variations by race/ ethnicity. Comprehensive Psychiatry, 53(6), 657-665. https://doi. org/10.1016/j.comppsych.2011.10.002.

Michaels, T. I., Purdon, J., Collins, A., \& Williams, M. T. (2018). Inclusion of people of color in psychedelic-assisted psychotherapy: A review of the literature. BMC Psychiatry, 18(1), 245. https://doi.org/10.1186/s12888-018-1824-6.

Mithoefer, M. C., Feduccia, A. A., Jerome, L., Mithoefer, A., Wagner, M., Walsh, Z., et al. (2019). MDMA-assisted psychotherapy for treatment of PTSD: Study design and rationale for phase 3 trials based on pooled analysis of six phase 2 randomized controlled trials. Psychopharmacology, 236(9), 2735-2745. https:// doi.org/10.1007/s00213-019-05249-5.

Moreno, F. A., Wiegand, C. B., Taitano, E. K., \& Delgado, P. L. (2006). Safety, tolerability, and efficacy of psilocybin in 9 patients with obsessive-compulsive disorder. Journal of Clinical Psychiatry, 67(11), 1735-1740. https://doi.org/10.4088/jcp. v67n1110.

Nemu, D. (2019). Getting high with the most high: Entheogens in the old Testament. Journal of Psychedelic Studies, 3(2), 117-132. https://doi.org/10.1556/2054.2019.004.

Nichols, D. E. (2004). Hallucinogens. Pharmacology \& Therapeutics, 101(2), 131-181. https://doi.org/10.1016/j.pharmthera. 2003.11.002.

Ot'alora G, M., Grigsby, J., Poulter, B., Van Derveer, III, J. W., Giron, S. G., Jerome, L., et al. (2018). 3, 4-Methylenedioxymethamphetamine-assisted psychotherapy for treatment of chronic posttraumatic stress disorder: A randomized phase 2 controlled trial. Journal of Psychopharmacology, 32(12), 12951307. https://doi.org/10.1177/0269881118806297.

Palamar, J. J., Mauro, P. M., Han, B. H., \& Martins, S. S. (2017). Shifting characteristics of ecstasy users ages 12-34 in the United States, 2007-2014. Drug and Alcohol Dependence, 181, 20-24. https://doi.org/10.1016/j.drugalcdep.2017.09.011.

Park, A. (2019). Psychedelic drugs and the fine arts in the 1960s and 1970s. Ibid. A Student History Journal, 12.

Patterson, P. (2019). FDA grants Breakthrough Therapy Designation to Usona Institute's psilocybin program for major depressive disorder. Business Wire. https://businesswire.com/ 
news/home/20191122005452/en/FDA-grants-BreakthroughTherapy-Designation-Usona-Institutes.

Pouget, E. R., Fong, C., \& Rosenblum, A. (2018). Racial/ethnic differences in prevalence trends for heroin use and nonmedical use of prescription opioids among entrants to opioid treatment programs, 2005-2016. Substance Use \& Misuse, 53(2), 290-300. https://doi.org/10.1080/10826084.2017. 1334070.

Pugh, L. A., \& Bry, B. H. (2007). The protective effects of ethnic identity for alcohol and marijuana use among Black young adults. Cultural Diversity and Ethnic Minority Psychology, 13(2), 187. https://doi.org/10.1037/1099-9809.13. 2.187.

Richman, L. S., Boynton, M. H., Costanzo, P., \& Banas, K. (2013). Interactive effects of discrimination and racial identity on alcohol-related thoughts and use. Basic and Applied Social Psychology, 35(4), 396-407. https://doi.org/10.1080/01973533. 2013.803966.

Rigg, K. K. (2017). Motivations for using MDMA (Ecstasy/Molly) among African Americans: Implications for prevention and harm-reduction programs. Journal of Psychoactive Drugs, 49(3), 192-200. https://doi.org/10.1080/02791072.2017. 1305518.

Rosino, M. L., \& Hughey, M. W. (2018). The war on drugs, racial meanings, and structural racism: A holistic and reproductive approach. American Journal of Economics and Sociology, 77(34), 849-892. https://doi.org/10.1111/ajes.12228.

Sawyer, W. \& Wagner, P. (2020). Mass incarceration: The whole pie 2020. Prison Policy Initiative.

Schulenberg, J. E., Johnston, L. D., O’Malley, P. M., Bachman, J. G., Miech, R. A., \& Patrick, M. E. (2020). Monitoring the Future national survey results on drug use, 1975-2019: Volume II, College students and adults ages 19-60. Ann Arbor: Institute for Social Research, The University of Michigan. http:// monitoringthefuture.org/pubs.html\#monographs.

Sessa, B., Higbed, L., O’Brien, S., Durant, C., Sakal, C., Titheradge, D., et al. (2021). First study of safety and tolerability of 3,4methylenedioxymethamphetamine-assisted psychotherapy in patients with alcohol use disorder. Journal of Psychopharmacology (Oxford, England), 35(4), 375-383. https://doi.org/10. $1177 / 0269881121991792$.

Shalit, N., Rehm, J., \& Lev-Ran, S. (2019). Epidemiology of hallucinogen use in the U.S. results from the National epidemiologic survey on alcohol and related conditions III. Addictive Behaviors, 89, 35-43. https://doi.org/10.1016/j.addbeh.2018.09. 020.

Substance Abuse and Mental Health Services Administration (2018). National survey on drug use and health 2018. Department of Health and Human Services, SAMHSA, Center for Behavioral Health Statistics and Quality. (NSDUH-2018DS0001). https://www.datafiles.samhsa.gov/study/nationalsurvey-drug-use-and-health-nsduh-2018-nid18757.

Substance Abuse and Mental Health Services Administration. (2019). 2018 national survey on drug use and health: Methodological summary and definitions. Center for Behavioral Health Statistics and Quality, Substance Abuse and Mental Health Services Administration. Retrieved from https://www.samhsa. gov/data/.
Tamir, C. (2021) The growing diversity of Black America. Pew Research Center.

Tate, C., \& Audette, D. (2001). Theory and research on 'Race' as a natural kind variable in psychology. Theory \& Psychology, 11(4), 495-520. https://doi.org/10.1177/09593543011 14005.

Thomas, G., Lucas, P., Capler, N. R., Tupper, K. W., \& Martin, G. (2013). Ayahuasca-assisted therapy for addiction: Results from a preliminary observational study in Canada. Current Drug Abuse Reviews, 6(1), 30-42. https://doi.org/10.2174/ 15733998113099990003.

Tonry, M. (2010). The social, psychological, and political causes of racial disparities in the American criminal justice system. Crime and Justice, 39(1), 273-312. https://doi.org/10.1086/ 653045.

Uhlmann, E., Dasgupta, N., Elgueta, A., Greenwald, A. G., \& Swanson, J. (2002). Subgroup prejudice based on skin color among Hispanics in the United States and Latin America. Social Cognition, 20(3), 198-226. https://doi.org/10.1521/soco.20.3. 198.21104.

United States Census Bureau. (2012). 2010 census shows multiplerace population grew faster than single-race population. News Releases. https://www.census.gov/prod/cen2010/briefs/c2010br13.pdf.

U.S. Census Bureau. (2019). QuickFacts: United States. [Data set]. https://www.census.gov/quickfacts/fact/table/US/PST045219.

Virani, H. N. \& Haines-Saah, R. J. (2019). Drug decriminalization: A matter of justice and equity, not just health. American Journal of Preventive Medicine, 58(1), 161-164. https://doi.org/ 10.1016/j.amepre.2019.08.012.

Webster, P. (1999). The road to Eleusis: Unveiling the secret of the mysteries. Twentieth Anniversary Edition, by R. Gordon Wasson, Albert Hofmann, Carl A.P. Ruck, Hermes Press, 1998. (Originally published by Harcourt Brace Jovanovich in 1978). ISBN 0-915148-20-X [Review of The Road to Eleusis: Unveiling the Secret of the Mysteries. Twentieth Anniversary Edition, by R. Gordon Wasson, Albert Hofmann, Carl A.P. Ruck, Hermes Press, 1998. ISBN 0-915148-20-X]. International Journal of Drug Policy, 10(2), 157-166. Elsevier B.V. https://doi.org/10. 1016/S0955-3959(99)00012-2.

Welch, K., Payne, A. A., Chiricos, T., \& Gertz, M. (2011). The typification of Hispanics as criminals and support for punitive crime control policies. Social Science Research, 40(3), 822-840. https://doi.org/10.1016/j.ssresearch.2010.09. 012.

White, K. M. (2015). The salience of skin tone: Effects on the exercise of police enforcement authority. Ethnic and Racial Studies, 38(6), 993-1010. https://doi.org/10.1080/01419870. 2014.952752 .

Williams, M. T. (2021). Why Black people should embrace psychedelic healing. In B. Labate \& C. Cavnar (Eds.), Psychedelic justice: On gender, diversity, sustainability, reciprocity, and cultural appropriation. Synergetic Press. ISBN: 978-090779185-0.

Williams, M., Davis, A., Xin, Y., Sepeda, N., Colon-Grigas, P., Sinnott, S., et al. (2021). People of color in North America report improvements in racial trauma and mental health symptoms following psychedelic experiences. Drugs: Education, 
Prevention \& Policy, 28(3), 215-226. https://doi.org/10.1080/ 09687637.2020.1854688.

Wu, L. T., Woody, G. E., Yang, C., Pan, J. J., \& Blazer, D. G. (2011). Racial/ethnic variations in substance-related disorders among adolescents in the United States. Archives of General Psychiatry, 68(11), 1176-1185. https://doi.org/10.1001/archgenpsychiatry. 2011.120.
Yensen, R. (1985). LSD and psychotherapy. Journal of Psychoactive Drugs, 17(4), 267-278. https://doi.org/10.1080/02791072.1985. 10524331.

Young, R. S., \& Joe, J. R. (2009). Some thoughts about the epidemiology of alcohol and drug use among American Indian/Alaska Native populations. Journal of Ethnicity in Substance Abuse, 8(3), 223-241. https://doi.org/10.1080/15332640903110443.

Open Access. This is an open-access article distributed under the terms of the Creative Commons Attribution-NonCommercial 4.0 International License (https:// creativecommons.org/licenses/by-nc/4.0/), which permits unrestricted use, distribution, and reproduction in any medium for non-commercial purposes, provided the original author and source are credited, a link to the CC License is provided, and changes - if any - are indicated. 